\title{
Jejunal MALT (Mucosa Associated Lymphoid Tissue) Lymphoma: A Case Report
}

\author{
Daniel Ardian Soeselo ${ }^{1,2,3}$, Stephanie ${ }^{1}$, Dyonesia Arie Harjanti ${ }^{2}$ \\ ${ }^{1}$ Department of Surgery, School of Medicine and Health Science, Atma Jaya Catholic University of Indonesia, Jakarta, \\ Indonesia \\ ${ }^{2}$ Department of Surgery, Puri Indah Hospital, Jakarta, Indonesia \\ ${ }^{3}$ Department of Anatomical Pathology, School of Medicine and Health Science, Atma Jaya Catholic University of \\ Indonesia, Jakarta, Indonesia
}

\section{ARTICLE INFO}

Article history:

Received : 14 October 2018

Reviewed: 14 November 2018

Accepted : 06 February 2019

\section{Keywords:}

Helicobacter pylori, jejunal

perforation, MALT lymphoma

\section{*Corresponding author:}

Stephanie

Atma Jaya School of Medicine and

Health Science

Email: alexaniesu@gmail.com

\begin{abstract}
A BSTRACT
Background: MALT (Mucosa Associated Lymphoid Tissue) Lymphoma is an uncommon condition. It is an involvement of extranodal site in hematologic malignancy, NonHodgkin Lymphoma.
\end{abstract}

Case Presentation: Pondok Indah, Puri Indah Hospital Jakarta treated a 38-year-old female with acute abdomen due to jejunal MALT Lymphoma perforation, one meter from treitz ligament. Emergency laparotomy was performed, the patient had a resection and end to end anastomose. She was hospitalized in intensive care unit for 4 days after the surgery and died because of prolonged septic shock.

\begin{abstract}
Conclusions: MALT lymphoma is an uncommon condition which is often encountered in emergency conditions due to acute abdominal pain caused by intra-abdominal perforation of the hollow viscus. Late diagnosis and treatment may cause severe outcome such as perforation and hypovolemic shock. This case report is expected to provide insight and to increase the awareness of the incidence of jejunal MALT lymphoma in Indonesia.
\end{abstract}

\section{INTRODUCTION}

Non-Hodgkin lymphoma (NHL) is a well-known hematologic malignancy (1). Gastrointestinal tract (GIT) is the most common extra nodal site involved by lymphoma. Jejunal-mucosa associated lymphoid tissue (MALT) lymphomas are uncommon, accounting for $5 \%$ $20 \%$ of all NHL (2). MALT lymphoma is the prototype seen in association with Helicobacter pylori ( $H$. pylori) (1). GIT lymphomas are most frequently located in the stomach followed by small intestine and ileocecal region (2). However, primary GIT lymphoma is very rare compared to secondary GIT lymphoma, constituting of $1 \%-4 \%$ of all GIT malignancies $(2,3)$. Primary small intestinal malignant tumors are equally rare, constituting of less than $2 \%$ of all tumors of GIT, of which $15 \%-20 \%$ are primary small intestinal lymphoma (2).

Small intestinal lymphomas are heterogeneous and the majority are NHLs, B cell dominating over $\mathrm{T}$ cell type. B cell lymphomas are classified into MALT lymphoma, diffuse large B cell Lymphoma (DLBL) with or without a MALT component, immunoproliferative small intestinal disease (IPSID), follicular lymphoma, mantle cell lymphoma, Burkitt lymphoma, lymphomas and lymphoid proliferations associated with immunodeficiency; while $T$ cell lymphomas are the enteropathy associated $\mathrm{T}$ cell lymphoma (EATL), and other types unassociated with enteropathy and nasal type NK cell lymphoma $(2,4,5)$.

From all these lymphomas, DLBL is the most common in essentially all sites and most aggressive, while MALT type is the most uncommon indolent subtype which represents $7 \%$ of all non-Hodgkin's lymphomas. Most of MALT lymphomas of the small intestine occur in the ileum $(60 \%-65 \%)$ followed by jejunum (20\%-25\%), duodenum $(6 \%-8 \%)$ and other sites $(8 \%-9 \%)(2,5)$.

\section{CASE PRESENTATION}

A female, 38-year-old came to emergency room with severe abdominal pain since 2 days prior to admission. The pain appeared suddenly in upper part of the abdomen and became worse. No history of analgesic or steroid medication. No history of previous illness such 
as cancer, lump, coagulation disorder and abdominal discomfort. The patient had no fever, weight loss, vomiting or nausea, and eating disorder. She did not have a family history of cancer. In emergency room, she looked weak with septic shock condition and her BMI was in a moderate obesity. On physical examination, abdominal guarding was found. The laboratory findings showed: leucocytes 18.000/ $\mu$; hemoglobin 10,2 gr/dL; protrombin time 16,3 second $(9,3-11,4)$; APTT (activated partial tromboplastin time) 67,6 (25-40); ureum $101 \mathrm{mg} / \mathrm{dL}$; creatinine 2,57 mg/dL; lactat 4,7 $\mathrm{mmol} / \mathrm{L}$; widal test was negative; tubex score 2. H. pylori IgG was $37 \mathrm{RU}$ per cc. IgM H. pylori was negative. Abdominal ultrasound found accumulation of intraabdominal free fluid. The abdominal CT-Scan showed fluid accumulation.

Emergency laparotomy was performed. Perforation of jejunum about 1 meter from treitz ligament was found. Intrabdominal condition was very dirty and the operation was continued with the small bowel resection and an end-to-end anastomosis. She was hospitalized in intensive care unit and passed away 4 days after the surgery because of prolonged septic shock.

Microscopic pathological finding on $\mathrm{HE}$ staining found erosive, ulcerative mucous of small intestine indicating perforation with diffused tumor mass showing transmural monotonous centrocyte and some imunoblast around the perforation area. Jejunal Giemsa Stain in 50x magnifaction showed lots of $H$. pylori. Further examination of immunophenotypes profiling found that the lymphoma cells were CD $20(+)$ and CD 3 $(-)$.

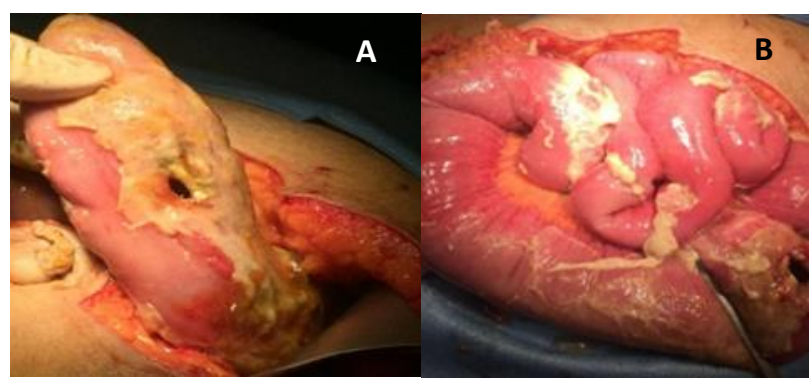

Figure 1. (A) Perforated jejunal; (B) Perforated jejunal with excessive amount of fibrin

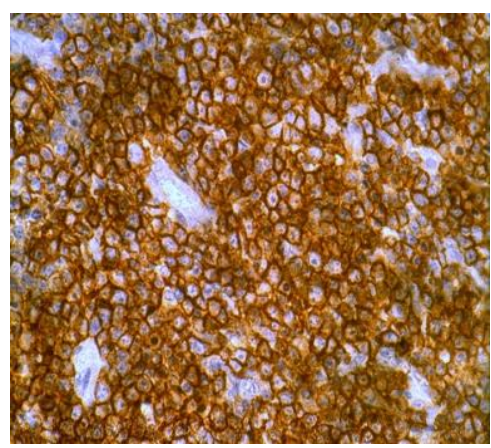

Figure 2. Tumor cells showed positive reaction towards CD 20 immunoreactivity (membrane)

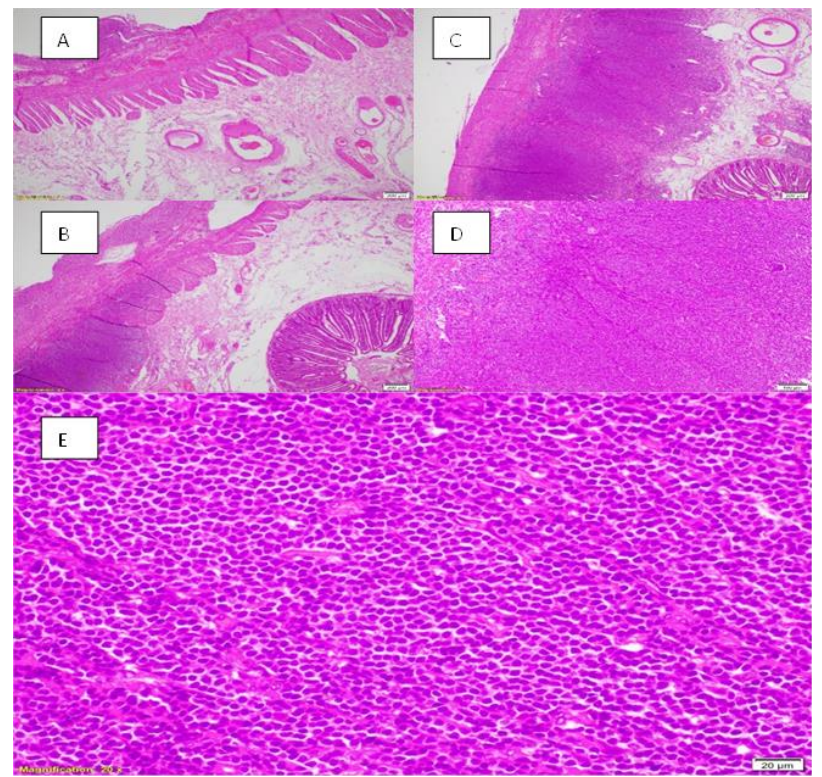

Figure 3. (A) Normal mucosal Jejunal with HE stain in $2 x$ magnification; (B) Borderline of normal to tumor mass of mucosal jejunal in HE stain $2 x$ magnification; (C) Jejunal tumor mass with HE stain in $2 x$ magnification; (D) Jejunal tumor mass with $\mathrm{HE}$ stain in $5 x$ magnification; (E) Heterogenous diffusion of small B cells (centrocyte like) in jejunal epithelial tissue with $\mathrm{HE}$ stain in 20x magnification.

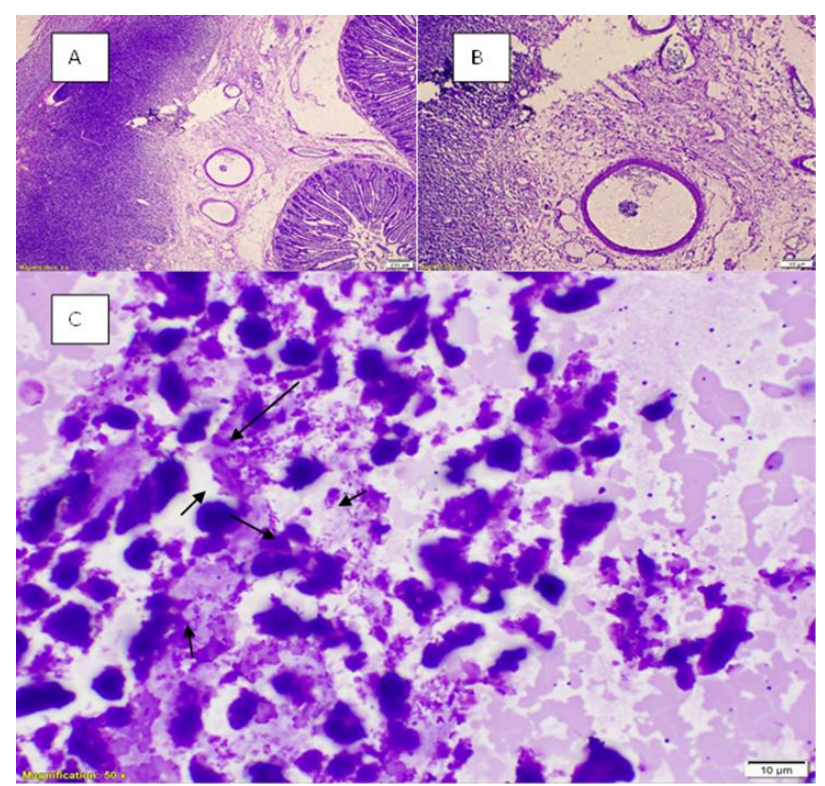

Figure 4. (A) Jejunal giemsa stain in $2 x$ magnification; (B) Jejunal giemsa stain in $5 x$ magnification; (C) Jejunal giemsa stain in 50x magnification with lots of $H$. pylori around the inflamation site

\section{DISCUSSION}

Extranodal marginal zone lymphoma of MALT lymphoma is composed of morphologically heterogeneous small B-cells including marginal zone centrocyte-like cells in epithelial tissues, with neoplastic cells typically infiltrating the epithelium forming 
lymphoepithelial lesions. MALT lymphoma is a unique tumor that originates from acquired MALT associated with chronic inflammation or autoimmune responses (6).

In the Revised European-American Classification of Lymphoid Neoplasms and World Health Organization classifications, MALT lymphomas are categorized as the most common type of marginal zone B-cell lymphoma. This lymphoma typically arises in locations with limited lymphoid tissue in the setting of chronic inflammation such as $H$. pylori associated chronic gastritis, follicular bronchiectasis in the lung, and Hashimoto thyroiditis. The extranodal sites that are typically affected include the stomach, small bowel, lung, eye, and salivary glands (7).

Predisposing factors for lymphoma of the small intestine include prior malabsorption syndromes (e.g. celiac sprue and dermatitis herpetiformis); inflammatory bowel disease (e.g. Crohn's disease) and congenital or acquired immunodeficiency states, including iatrogenic immunosuppression after organ or bone marrow transplantation (3).

MALT lymphoma usually presents as a localized disease but characteristically disseminates either within the same organ or to other extranodal sites in which MALT lymphomas are known to arise. There are two types of MALT lymphomas in disparate organs which do not correspond to the peripheral sites of the immune system: one is the native type consisting of lymphoid tissue that physiologically presents in the gut (e.g., Peyer patches), and the other is acquired MALT lymphoma that develops in sites of chronic inflammation in response to either infectious conditions (e.g., H. pylori gastritis) or autoimmune processes (e.g.,Hashimoto thyroiditis). These prolonged lymphoid reactive proliferations lead to the growth of a pathologic clone that progressively replaces the normal lymphoid population, resulting in a MALT lymphoma (7).

Patients commonly present with pain, loss of appetite, loss of weight, nausea, vomiting, anemia (due to bleeding), diarrhea, constipation, night sweats and fever. The presentation varies: there may be a palpable mass, gastrointestinal hemorrhage, perforation, but small-bowel obstruction is uncommon (7).

Most of the tumors were diagnosed by diagnostic endoscopy such as upper endoscopy, video capsule endoscopy and balloon assisted enteroscopy (41\%) or imaging techniques (35\%) such as computed tomography (CT) techniques which is the main imaging method for diagnosis, followed by ultrasound and magnetic resonance imaging (8). In active bleeding patients, biopsies could not be performed endoscopically and the histological diagnosis could only be obtained after the surgery $(9,10)$.

Furthermore, MALT lymphoma can be diagnosed based on the histopathological feature of small cell lymphoma, and the profile of immunostaining of the lymphoma cells, using B-cell marker CD20, T-cell markers (CD3 and CD5) and markers of germinal center B-cell (bcl-6 and CD10) (3).

In our case, the patient came to hospital with an acute abdominal pain due to intra-abdominal perforation of the hollow viscus because we found abdominal guarding on physical examination, leukocytosis on laboratory finding and accumulation of intra-abdominal free fluid on abdominal ultrasound. Other diagnostic test such as endoscopy and CT scan were not performed because of financial limitation.

On low-power microscopy of a histologic specimen, MALT lymphoma is characterized by expansion of the marginal zone with preservation of the lymphoid follicles. At high power, polymorphous infiltrate of small round lymphocytes, monocytoid or plasmacytoid lymphocytes, and lymphoepithelial lesions are typically observed (10).

Characteristic findings based on immunohistochemistry (IHC) are important in differentiating MALT lymphoma from other low-grade non-Hodgkin's lymphoma including leukocyte's common antigen. The characters are CD45(+), CD20(+), CD79a(+), $\operatorname{CD} 5(-), \operatorname{CD} 10(-)$, and CD23(-) and the presence of $\lambda$ and $\mathrm{K}$ light-chain restriction. MALT lymphoma is often diagnosed by exclusion of other small B-cell lymphomas. For example, follicular lymphoma shows CD10(+); small lymphocytic lymphoma shows CD5(+) and CD23(+); and mantle cell lymphoma shows CD5(+), CD23(+) and cyclin D1(+). Biopsy of the lesion, IHC, and cytogenetic studies are therefore essential to establish the correct diagnosis (10). In our case, we found CD 20 (+) and CD 3 (-) from IHC examination which support the diagnosis of MALT lymphoma B cell type. The prognosis of extranodal marginal zone lymphoma (MALT type) is excellent with a 5 -year survival rate of $>90 \%$ and 10 -year survival rate of $75 \%-80 \%$, but MALT lymphoma of the intestine is worse than gastric type with a 5 -year survival rate of $44 \%-75 \%$ $(2,9)$.

\section{CONCLUSIONS}

MALT is a very rare case. We find a complicated intrabdominal intestinal perforation cause by malt perforation. We can prevent this event if we could give early information and education to the patient with abdominal pain to do esophagogastroduodenoscopy as a preventive diagnosis.

Diagnosis of MALT Lymphoma was made by histopathology and IHC examination. We reported an incidental jejunal MALT lymphoma perforation. We diagnosed jejunal MALT Lymphoma by finding heterogenous diffusion of small B cell (centrocyte like) in jejunal epithelial tissue and $H$. pylori around the inflammation site at histopathologic examination. 


\section{Acknowledgement}

We thanked Grace, MD as the pathologist of Pondok Indah, Puri Indah Hospital for providing histopathologic examination and Liza Suryani MD, as a pathologist, for providing immunohistochemistry examination.

\section{REFERENCES}

1. Abbas H, Niazi M, Makker J. Mucosa-associated lymphoid tissue (malt) lymphoma of the colon: a case report and a literature review. Am J Case Rep. 2017;18:491-7.

2. Ezejiofor IF, Ogbu CC, Onwukamuche ME, et all. Primary B-cell jejunal maltoma in a young adult male: a case report and review of literature. $\mathrm{N}$ Niger J Clin Res. 2017;6(10):57-60

3. Fischbach W. Gastric MALT Iymphoma-update on diagnosis and treatment. Elsevier. 2014;28(6):106977

4. Chen C-T, Yen H-H, Wu L. Primisary jejunal mucosaassociated lymphoid tissue lymphoma. QJM Int J Med. 2013;106(2):195-6.

5. Shirsat HS, Vaiphei K. Primary gastrointestinal lymphomas - A study of 81 Cases from a Tertiary Healthcare Centre. Indian J Cancer 2014;51(3):290.
6. Albahadili MA, Hadi A, Louy H. Jejunum maltoma presented with perforation masked by dexamethazone abuse complicated by wound dehiscence managed with Ozone (O3) therapy. Int J Med Res Prof. 2015;1(3):54-57

7. Hayashi D, Devenney-Cakir B, Lee JC, et all. Mucosa-associated lymphoid tissue lymphoma: multimodality imaging and histopathologic correlation. AJR Am J Roentgenol. 2010;195(2):W105-117.

8. Lo Re G, Federica V, Midiri F, et all. Review article: radiological Features of Gastrointestinal Lymphoma. Gastroenterology Research and Practice. 2016;2498143:9. DOI: https://www.hindawi.com/journals/grp/2016/2498 143/abs/

9. Cardoso H, Rodrigues JT, Marques M, et all. Malignant small bowel tumors: diagnosis, management and prognosis. Acta Médica Port. 2015;28(4):448-56.

10. Hayashi D, Devenney-Cakir B, Lee JC, et all. Mucosa-associated lymphoid tissue lymphoma: multimodality imaging and histopathologic correlation. Am J Roentgenol. 2010;195(2):W10517. 